\title{
Vectors of Students' Practice-Oriented Professional Training in Teacher Education Universities
}

\author{
Natal'ya D. Koletvinova ${ }^{1}$ \\ ${ }^{1}$ Kazan (Volga region) Federal University, Kazan, Russia \\ Correspondence: Natal'ya D. Koletvinova, Kazan (Volga region) Federal University, Kremlyovskaya Street 18, \\ Kazan, 420008, Russia.
}

Received: December 29, 2014

Accepted: January 22, 2015 Online Published: February 11, 2015

doi: $10.5539 /$ res.v7n4p59

URL: http://dx.doi.org/10.5539/res.v7n4p59

\begin{abstract}
The relevance of this problem is caused by insufficient degree of elaboration of the theoretical and practical foundations of practice-oriented professional training for students in teacher education universities. Currently, the labor market demands competitive teachers who have mastered the necessary and sufficient types of professional communicative activities with an adequate speech design. The purpose of the study is to develop framework-components to improve the efficiency of designing multi-level professional communication situations. The leading research technologies are designing, intellectual communication, implementation of integration relations, person-centered communication, and others. The article reflects the results of the work done, in which students have mastered a typical structure of professional designing, learned to choose the right forms of intellectual communication in accordance with their academic and educational orientation, mastered the competence of multi-level professional communication. The article submissions may be useful for practical professional activities of university and high school teachers.
\end{abstract}

Keywords: designing, microtext, formation, tests, fragment, frame, adequacy of speech design, clichéd samples, standard texts, structural components, integration relations, person-oriented communication, language means, information-training complex, speech act

\section{Introduction}

Improvement of modern higher education in recent years is largely due to the innovative approach to the process of professional training.

At present, the scientific community places greater demands on the teacher's professional activity in market conditions (Zakirova, 2014). This is manifested in strengthening the fundamental nature of the professional training process, which dictates "deepening of the general theoretical, educational, as well as general scientific and professional training of students and the expansion of their professional training profile" (Popov, 2008).

However, despite the understanding of the complexity of the problem of future teachers' professional training and the tendency to consider this process from the perspective of the content updates, there has not been a significant breakthrough in the effectiveness of the specialist training (Andreev, 2012). If to consider the proposition that "universities today - are not just educational institutions but also scientific research centers" as a starting point, then the vector of students' professional training will focus on strengthening its research foundation (Namsaraev, 2008). This, in turn, will also change and update the substantive-procedural resources for professional communicative competence development." The main vector for organizing such pedagogical process is formation of professionally-competent graduates, who are capable to solve various problems ..." (Afanasiev, 2013).

Designing situations of professional communication takes a special place in the practice-oriented system of professional communicative competence development, as it opens great opportunities to the students for independent designing various types of the teacher's speech activities taking into account his/her individual and personal potential and professionally-personal qualities development.

\section{Methodological Framework}

The problem of the specialist professional training is currently in the focus of public attention. In universities of the world there are programs being implemented, based on methods of active learning, which is centered on the 
student (Kolmos, 2004). An issue raises on the University's maintaining "reflection on the ethical commitments and social consequences of each profession" (Rbodes, 2001).

Much attention is paid to innovative interpretations of pedagogical technologies, methods, techniques, principles and approaches: research technology, project technology, methods of integration relations implementation and others. As a unifying principle of scholars' academic views stands out the requirement of continuous improvement of diagnostic tools, of primary and secondary students' professional training processes, the striving to organize a learning process based on self-organization, self-education and self-development (Andreev, 2013). This will allow future teachers to further successfully solve the problem of the forming students' intellectual self-cognition and self-enquiry qualities. In addition, the effectiveness of the specialist training is directly related to the professional practice-oriented designing technology. It focuses on the acquisition of necessary and sufficient expertise. As a result of that an educational space complete picture emerges, with the necessary and sufficient value systems, aimed at developing students' attitudes toward training throughout life (Leavitt, 1989).

\section{Results}

\subsection{Objectives of Professional Practice-Oriented Training of Students}

One of the important problems of professional orientation of training remains the problem of practice-based learning in the context of the requirements of modern education. This is due to the requirements of improving the effectiveness of future specialists training. Among the variety of professional orientation technologies for training in this article the priority part is assigned to the designing technology, which enables detailed mastering various kinds of teacher's professional work on the basis of realization of his/her creative abilities.

The first objective is performed by the task of students' understanding the expediency of element-wise and gradual mastering the professional activities with adequate speech design. Without that the practice-oriented training remains for students as an extra learning complexity. The second objective is to determine the functional characteristics of frames and their role in professional practice-oriented training of students. The third objective is to derive indicators of situationally conditioned professional activities with adequate speech design. And it is necessary to be aware that the adequacy of speech design - is a non-permanent category, calls for increased mental activity and sufficient vocabulary. The fourth objective is to create special creative tasks-test frames - with a specific target setting, performance criteria, speech designing tools of activities aimed at developing professional competence and professionally-personal qualities of a specialist.

To achieve the stated objectives a special framework complex for professional analytical designing the professional activities was developed, being related to a frame-designing form (Minsky, 1980).

\subsection{Practice-Oriented Designing of the Main Types of Professional Activities}

At the first stage of professional practice-oriented training the activities of a teacher in the context of their professional conditionality and speech-content are analyzed.

At the beginning of the work there was diagnostics carried out to determine the level of psychological readiness of students to perceive versatile professionally-oriented material of various specific kinds, as well as the level of professional orientation vocabulary, knowledge of professional speech peculiarities.

The diagnostics showed insufficient psychological readiness of students to perceive the practice-oriented material, lack of professional realia knowledge, lack of the differentiated approach to the distribution of professional activities according to their target settings and substantive-procedural orientation. In accordance with this, there have been developed special professionally oriented tasks of primary difficulty, which cover the primary levels enabling students to practice-oriented professional training process. It includes tests, thematic situation-based tasks, and questions for reflection. As the main form of education here is a form of designing professional activities in the context of his/her professional competence and development of a creative personality of the future teacher (Zimnyaya, 2005; Boström, 2013; Thomas, 2012).

Priority is assigned to technologies of motivational grounding the activities being designed, as well as to methods of aspect-integrated learning, adaptation techniques, reflexive methods, the implementation of integration relations and others. By analyzing each component, students independently choose to design a material that allows them to use a variety of strategies, tactics, ways, and techniques. Each mini-project is publicly discussed, the adequacy of speech design is determined, motivation of the activities, the personal qualities of students are stated, which are formed in the course of educational activity, the effectiveness of the performed work is assessed. Students get satisfaction from such work, gradually accumulating experience for future professional activity (McKenzie, 2011). At the first stage designing the activities is carried out with strict regard to their speech content. Thus the students' knowledge of the specialty language, the metalanguage is 
consolidated. The used preparatory-rehearsal character of practice-oriented professional training of students is seen as a creation of primary professional data bank, which can later be used as a basis for carrying out further more complex work on professional training. The effectiveness of this work is due to the active help of teachers who implement feedback followed by a discussion at every stage (Race, 1993).

\subsection{Features of Frame Designing}

The effectiveness of students' mastering the types of professional speech communication activities largely depends on the choice of practice-oriented training forms. The priority role at the second stage is given to frame designing. By frames we understand certain forms and activities of fragmented nature, used in the initial and continuing training phases. Each frame represents fragmentary acts of professional activities, has its own goals and objectives, and performs its control and evaluation function.

At this stage the priority status is given to communicative technology, differentiation of language means, designing method, research method, reflexive method, implementation of integration relations method. The work is organized around the development of students' understanding the multifunctionality of a teacher's professional activity. For this purpose, specially developed cycles of frames are used: frame-presentation, frame-conversation, frame-discussion, frame-lab work and others.

The priority in these kinds of works is given to the encouraging and supporting intrinsic motivation principle (Conner, 2006). Based on the cycles of framed designing, students prepare fragments of a class presentation on the chosen topic with the implementation of contextual guessing methods, and implementation of integration relations; make a speech on the reviewed material, justifying and proving the correctness of independently selected professional activities with adequate speech design. Frame discussion develops such qualities in students as self-enquiry, self-evaluation, self-organization, and self-identification. The frame conversations largely contribute to the development of competence components of multi-level nature dialogized interaction and organizational skills to manage professional communication (Kaminskaya, 2003).

The formation of these qualities contributes to developing a creative personality of a future teacher, his/her competitiveness, as well as the desire for self-mastering professional competences which meet the needs of modern society (Implementation, 2010).

The stage concludes with a test during which designing the situation-based activities with adequate speech design is independently performed. After that, there is group discussion held with commentaries and estimation of their activities.

\subsection{The Use of Test-Frames as a Factor in the Effectiveness of Students' Professional Training}

The third stage of professional practice-based learning is based on a test-frame designing. The priority is given here to competence-forming technologies, criteria technologies, integration relations implementation technologies. At this stage, it is advisable to carry out multi-level work on mastering functional-semantic types of speech activity.

Work on test frames that relate to professional activities is aimed at element-wise mastering the basic components of multi-level types of professional activities in the context of realizing students' individual abilities and developing their personal professionally-oriented qualities of self-activating. When performing a test-frame of fragmented designing communicative and speech acts of substitution nature, the target setting for the students was to determine the teachers' and students' interaction function maturity. Informational, diagnostic, stimulating, and evaluating functions were being defined. As the performance criteria there were proposed options for certain types of activities with the indication of speech design. In the work process there were developed contact-establishing, informative and communicative competence components, individual and personal qualities of self-identification, self-selection, self-estimation and others.

When running a test-frame of transformation-fragmented nature, the target setting was to determine the level of switching from one speech sample to another, which promotes the development of competence for holding professional activities with adequate speech design. As a criterion of performing the test-frame there was the ability to convert a text, selecting in it the informative and communicative orientation. As the defining competency components the communicative-contacting, communicative-motivating ones can be included here, because the construction of coherent sentences with a clear separation of the main idea is aimed at encouraging students to actively participate in the work and manage the targeted audience.

Test-frame of fragmentary-reproductive nature is aimed at determining the level of independent composition of presenting new material fragments, taking into account the target audience. Designing these activities contributes to developing such professional communicative competence components as the communicative-stimulating 
component, communicative-contacting, communicative-cognitive component. This is achieved by awareness of the multifunctional types of professional activities features with different target settings, speech content and motivation.

\subsection{Test-Frames of Intellectually-Creative Nature}

At the fourth stage, students were performing test-frames and were mastering competency components of designing intellectual and creative nature activities. At this stage, the systematic approach was widely used, as well as cognitive approach, intellectual development technologies, the problem-search method, research method, and others. Specially developed tasks on test-frame designing were focused on the development of students' creative qualities. The target setting of test-frames of fragmentary-creative nature is based on determining the level of intellectual richness of problem lecture through the use of additional material. Criterial justification for this type of activity was the appropriate inclusion of supporting material in the speech composition of a particular type of professional activity. And speech design of activities should be based on individual character and include emotion-evaluative structures, individualized means of communication, that contribute to the manifestation of individual and personal qualities of the future teacher.

At this stage the following competency components are formed: communicatively-intellectual, communicatively-contacting, communicatively-motivating, organization-communicative, integration-communicative, and communicatively-creative. Each component of the professional competence includes an individually-personal creative element based on the research method and the method of contextual guessing.

The starting point for mastering the technology of intellectual and creative nature designing is the development of research skills technology, creative thinking technology, the technology of comparative analysis of situation-based teacher's multifunctional activities. Students take the floor on the analysis of professional and thematic issues, and actively get involved in the debate on topical issues of professional competence development, and problem-oriented discourses (Sleeman, 1992).

Test-frame of designing speech intellectual activity is based on such cognitive performance indicators as memory, perception, association and others. A special place in the intellectual communication is given to apperception because it is the result of such mental processes by which incoming information is related to already constructed conceptual system that is the impetus for developing cognitive independence of an individual (Miller, 1990). Designing the distribution of the intellectual information into the "studied" and the new one provides systematic acquisition of knowledge, promotes activation of cognitive processes in the context of including new obtained knowledge on a standalone basis, by implementing the integrational knowledge (Prince, 1981).

\subsection{Control-Evaluative Aspect of Professional Practice-Oriented Training of Students}

At the fifth stage, the control-evaluative function of the level of mastering the technology of designing professional activity of the future teacher is performed. During the control testing students were performing such actions which indicated of the implementation of the necessary and sufficient competency components of professional activity and professional competency development in general. Students were determining the type of professional activity with the justification of the adequacy of its speech design, were independently selecting the material for the class, justifying their choices, and were determining the type of speech activity with specification of language means. Designing the presentation fragments is accompanied by the use of axiological, ethical, aesthetic methods that enhance the educational focus of teaching material. Designing the fragments of professional speech activity was accompanied by the development of the future teachers' competence to take into account knowledge, interests, personality and social role of students, which is reflected in the modern education requirements. The students' responses are analyzed according to the following criteria: mastery of the transformative speech technology, the technology of designing versatile and multi-level professional activities, the implementing integration relations method, the aspect-integrated learning method, business games, the problem-search method, the research and intellectual communication method, the active communication principle method and others.

This allows considering the practice-oriented training as a basis for developing the teacher's professional communicative competence.

\section{Discussions}

Studies on the development field of students' professional readiness reflect the diversity of scientific views, a wide range of unexplored issues, pointing to the need to find optimal solutions. The essence of the educational competencies is deeply analyzed (Hutorskoy, 2007), the actual problem of the sociocultural competence is 
investigated (Lyurina, 2009), the psychological determinants of a person's professional motivation are carefully examined. Sufficiently fully examined are the classification of professional knowledge and skills performance indicators (Fedorov, 2009), the foundations of professional pedagogical communication, and elocution in teacher training (Savostianov, 2001). In the foreign scholars' concepts to develop specialist's training great attention is paid to ethical and reflective sides of professional activities (Rbodes, 2001), to the solution of professional practice-oriented problems (Vebter, 2010), attention is drawn to continuous improvement of diagnostic tools for training (Castro, 2009). The structure of professional orientation cooperative learning is considered by D. V. Johnson (Johnson, 1987).

However, there is no marked comprehensive solution to the problem of developing professional communicative competence. A number of issues still remain unexplored. These may include the features of professional non-linguistic departments students' practice-oriented teaching, research of framed designing specifics of professional activities with adequate speech design, reviewing of the designing technology as a condition for a personality's self-activation, and realization of their individual and personal abilities, and others.

This article is dedicated to the underdeveloped aspect of practice-oriented professional training based on an analytical frame design with prediction and perspective vision of results of the conducted educational activities.

In accordance with this there has been developed a system for designing professional activities with its component parts of universal professional nature. In this study the priority is given to frames comprising substantive-procedural material for holding professional activities with adequate speech design. The study showed the effectiveness of the choice of approaches and methods for facilitating the development of professional communicative training of future teachers. The majority of students were marked by a high level of competency components mastery of professional multi-level communication activities with adequate speech design.

Thus, the article reflects the results of the work done on the development of professional communicative competence on the basis of practice-based learning in the aspect of designing. The article submissions may be used in the practice of professional activities of university and high school teachers.

\section{Conclusions}

The results obtained in the course of systematic and purposeful work showed that the level of development of competency components meets modern education requirements and contributes to the development of a teacher's professional communicative competence. The students mastered the necessary and sufficient designing performance with adequate speech design, realized the need for goal-setting and motivation of each element of the designed professional activities, learned how to orient themselves in the functional space of the teachers' communicative action, in the selection of priority technologies, methods, forms and ways for carrying out professional activities with adequate speech design. The students were defining important competency components for the teaching profession, as well as personal qualities, independence qualities, analyzed the essence of the "designing professional activities" concept, the concept of "frame", the essence of the "test-frame" concept and others. The students demonstrated professional speech activity acquisition in the context of its adequacy for professional work types, dialogized communication mastery, discursive nature communication, intellectual communication through the implementation of the research method and the integration relations method. Methods, techniques, approaches and technologies were considered by the students in terms of their professional axiological, ethical, aesthetic potential, as well as creativity and relevance to the professional work of a teacher.

The conducted research led to the following conclusions: the systematic approach was accomplished on the issue of developing students' professional readiness on the basis of designing the professional activities. This allowed element-wise mastering the professional activities in terms of prediction and perspective analysis, their immediate results and further planning. The development indicators of professional communicative competence were derived, providing adequate speech design for all its components. Specific features of the test-framed designing were revealed, their aspect-speech richness, the relationship and interaction of all components of the multifunctional activity of a teacher. Technologies, methods, tools and ways for designing multi-level nature activities were identified. In the process of practice-based learning there was development of independent qualities in the context of modern requirements for training and education; the criterion validity of designing professional activities with adequate speech design was revealed. The use of the communicative, integrated, person-activity, creative and the research approaches in professional training of students as determinative ones in achieving efficient development of professional communicative competence in the practice-based learning process was analyzed. 


\section{Acknowledgments}

The work is performed according to the Russian Government Program of Competitive Growth of Kazan Federal University

\section{References}

Afanasiev, D. V., \& Gryzlov, V. S. (2013). Competence approach and credit-modular system of education. Higher education in Russia, 6, 11-18.

Andreev, V. I. (2012). A retrospective and predictive approaches to conceptualizing subjective-oriented pedagogical education for creative self-development of students-future teachers. Education and self-development, 5(33).

Andreev, V. I. (2013). Systematics of pedagogical and didactic laws, integratively oriented towards guaranteed quality of education. Education and self-development, 3(37).

Boström, L., \& Hallin, K. (2013). Learning Style Differences between Nursing and Teaching Students in Sweden: A Comparative Study. International Journal of Higher Education, 2(1), 22-34.

Castro, M. E., Niño, A., \& Muñoz-Caro, C. (2009). GMAT. A software tool for the computation of the rovibrational g matrix. Computer Physics Communications, 180(7), 1183-1187. http://dx.doi.org/10.1016/j.cpc.2009.01.006

Conner, M. (2006). Andragogy + Pedagogy. Retrieved from http://agelesslearner.com/intros/andragogy.html

Fedorov, A. V. (2009). Classification of professional knowledge and skills development indicators, necessary for teachers in media education. In Ways, means, upgrading the educational system possibilities (pp. 404-409). M.

Implementation of "Education and training 2010" work programme. (2010). Working group B: "Key Competences”. Key Competences for Lifelong Learning: A Europian Reference Framework. Retrieved from http://europa.eu.int/comm./education/policies/2010/doc/basicframe.pdf

Johnson, D. W., Johnson, R. T., \& Holubec, E. J. (1987). Structuring Cooperative Learning: Lesson Plans for Ts. Edina, Minn.

Kaminskaya, M. V. (2003). Pedagogical dialogue in the activity of a modern teacher. M.

Khutorskoy, A. V. (2007). Competencies in education. M.

Kolmos, A., Fink, F. K., \& Krogb, L. (2004). The Aalborg PBL model-Progress, Diversity and Challenges. Aalborg.

Leavitt, H. J. (1989). Educating our MBAs: On teaching what we haven't taught. California Management Review. 31(3), 38-50.

Lyurina, T. I., Lebedeva, A. V., \& Moskalenko, A. N. (2009). Structural and system-related understanding of the new education functions in modern dimension. In Ways, means, possibilities for modernizing the educational system (pp. 110-114). M.

McKenzie, J. (2001). How Teachers Learn Technology Best. The Educational Technology Journal, 10(6). Retrieved from http://fno.org/mar01/howlearn.html

Miller, G. A. (1990). Linguists, psychologists, and the cognitive science. Language, 66(2), $317-322$. http://dx.doi.org/10.2307/414889

Minsky, M. (1980). A framework for representing knowledge. In Frame conceptions and text understanding (pp. 1-25). B.

Namsaraev, B. (2008) "Baikal” scientific-research center. Higher education in Russia, 9, 59-62.

Popov, N. (2008). Fundamentalization of training specialists in mathematics in a university education. Higher education in Russia, 9, 32-35.

Race, Ph. (1993). Never mind the teaching_Feel the learning. SEDA Paper 80, June, Birmingham.

Rbodes, F. T. (2001). The creation of the future: The role of the American university (p. 34). Ithaca.

Savostianov, A. I. (2001). Elocution in professional teacher training. M.

Sleeman, D. (1992). Intelligent Tutoring Systems. New York.

Thomas, G. P. (2012) Metacognition in Science Education: Past, preset and future considerations. In B. J. Fraser, 
K. G. Tobin, \& C. J. McRobbie (Eds.), Second International Handbook of Science Education (pp. 131-144). Dordrecht: Springer. http://dx.doi.org/10.1007/978-1-4020-9041-7_11

Vebter, E. V., \& Safyannikov, I. A. (2010). Project-Organised Learning Method in the System of Engineering Education of Russia by the Example of National Research Tomsk Polytechnic University. In Second Ibero-American Symposium on Project Approaches in Engineering Education (PAEE'2010): Creating Meaningful Learning Environments (pp. 97-100). Barcelona.

Zakirova, V. G., \& Koletvinova, N. D. (2014). Paradigm of future primary school teachers' vocational training. Life Science Journal, 11(4), 441-447.

Zimnyaya, I. A. (2005). Educational Psychology: A textbook for higher schools. M.

\section{Copyrights}

Copyright for this article is retained by the author(s), with first publication rights granted to the journal. This is an open-access article distributed under the terms and conditions of the Creative Commons Attribution license (http://creativecommons.org/licenses/by/3.0/). 